\title{
Effect of Carbonization Time on the Morphology and Mechanical Properties of Natural Rubber Composites
}

\author{
*Momoh, F.P ${ }^{1}$; Mamza, P.A.P²; Gimba, C.E ${ }^{3}$; Nkeonye, $\mathrm{P}^{4}$. \\ ${ }^{I}$ Department of Polymer Technology, Auchi Polytechnic Auchi- Nigeria \\ ${ }^{2,3}$ Department of Chemistry, Ahmadu Bello University Zaria-Nigeria. \\ ${ }^{4}$ Department of Polymer and Textile Technology, Ahmadu Bello University, Zaria-Nigeria.
}

\begin{abstract}
This report is a followed up study of an earlier published work on Morphological Trends of Modified Coconut Fibre in Natural Rubber Reinforcement, where the Coconut Fibre was modified through the carbonization at varying temperatures of 300,400,500, 600, and $700^{\circ} \mathrm{C}$ for three (3) hours each. Evaluative examinations gave $600^{\circ} \mathrm{C}$ as the recommended best temperature at which significant performance of the composites could be achieved. In the present report carbonization was achieved at $600^{\circ} \mathrm{C}$ for a varying period of $1,2,3,4$ and 5 hours in order to evaluate the effect of carbonization time on the morphology and mechanical properties of the Coconut Fibre/Natural Rubber, composites. 100 $\mathrm{mm}$ particle sizes were achieved and characterization of both raw and treated fillers was effected prior to compounding. A remarkable improvement in the parameters evaluated was observed strongly at 3hours and fairly strong at 4hours for a carbonization temperature of $600^{\circ} \mathrm{C}$. Above 3 hours, a gradual deterioration of qualitative properties set in. The results showed that the time cycle for carbonization must be strictly monitored in order to achieve optimum modification in the use of coconut fibre for reinforced composites and as an alternative material for Shock bearings, Industrial fluid hoses, Ship liners and vast coverage areas in Automobiles.
\end{abstract}

Keywords: carbonization, composites, fibres, morphology, rubber.

\section{Introduction}

The use of both natural and synthetic fibres is one of the fastest and recently exploited reinforcement materials for natural rubber in the design of engineering and commodity wares. Natural rubber has certain best fit properties, but properties improvements and modifications cannot be overemphasized especially in line with modern technological breakthrough needed on the field of Polymer Science and Technology. This growth in the use of fibres is attributed to their attractive combination of low cost, low density, biodegradability, renewability and relatively high heat distortion temperature as well as relative chemical resistance. Currently aerospace, automotive and construction applications employ Polymer-Fibre Composites systems with loading levels ranging from 15 to $65 \%$ weight of fibre reinforcements. This approach improves most mechanical properties [15] Biomass in fibre or particulate form has been used as reinforcing filler in polymeric composites materials. However, they present limitations such as moisture adsorption and low thermal stability [6,3]. Generally, mechanical properties of the filler reinforced composites are mainly influenced by the interfacial adhesion between the fillers and the matrix polymer. Hydrophilicity represents a characteristic of the filler surface induced by the hydroxyl group for being able to interact with one another forming inter - and intra molecular hydrogen bonds. It is necessary to increase the compatibility between the hydrophilic fibre fillers and the hydrophobic Polymer matrix; hence the need for fibre modification $[7,8]$.

Other useful work that have been done in the use of fibres were from were on the evaluation of mechanical properties of coconut shell fibres as reinforcement material in epoxy matrix [9]; the mechanical properties of the coconut shell filler and epoxy composites [10]. Also reported was a work on the effect of filler content on properties of coconut shell filled polyester composites [11]. The results revealed that increased in coconut shell content have increased the tensile strength, young's modulus and the water absorption but reduced the elongation at break.

Onyeagoro carried out a research on cure characteristics and physico - mechanical properties of carbonized bamboo fibre filled natural rubber vulcanisates [12]. Ayo et al also investigated the effect of carbonization temperature on the mechanical properties of groundnut shell filled natural rubber composite [13]. The results obtained from these studies indicated a potential for the use of coconut fibre as fillers in composites preparations. In this present study, the effect of carbonization time at a best fit temperature of $600^{\circ} \mathrm{C}$ on coconut fibre - rubber matrix is examined. 


\subsection{Materials}

\section{Experimental}

Natural rubber of grade TSR 10 was obtained from the Rubber Research Institute of Nigeria (RRIN), Iyanomo, Benin City. All compounding additives such as Zinc oxide, Stearic acid, Sulphur, MBTS, TMTD and Mineral oil were of commercial grades. Coconut fibre was obtained as waste materials from Auchi in Edo State, Nigeria.

\subsection{Preparation of Coconut Fibre Filler and Carbonization Process}

The coconut shell fibre wastes were collected in large quantities, washed to remove sands and debris as much as possible. The washed fibre was oven-dried at $95^{\circ} \mathrm{C}$ for 2 hours to eliminate moisture and then properly dried prior to mill grinding and to improve the efficiency of carbonization. Five (5) portions of $250 \mathrm{~g}$ each were measured out for carbonization; while a $6^{\text {th }}$ portion of $200 \mathrm{~g}$ was left uncarbonized and was used as control sample. Carbonization was done at $600^{\circ} \mathrm{C}$ [5] for 1, 2, 3, 4,5hours and the spontaneous breakdown of the fibre was an exothermic process because energy was librated. This process of spontaneous breakdown continues until only the carbonized residue free from lignocelluloses and water remains. This process increased carbon content to about $75-85 \%$ and volatile content of about $10 \%$ [14-16].

All six (6) portions were ground and sequentially sieved to a $100 \mu \mathrm{m}$ particle size; characterized using standard ASTM methods and kept in air-tight containers prior to compounding.

\subsection{Characterization Methods}

To investigate the quality and processability of the particulate fibre achieved, ASTM standard methods for characterization were used to assess the $\mathrm{P}^{\mathrm{H}}$ value, percentage moisture retained, ash content, ignition tendencies, iodine value to determine surface area, bulk density, oil absorption, conductivity, lumen and dimensions of the sampled particles [17-19, 5]

\subsection{Compound Mix Process}

Appropriate formulation designs were made and the selected additives measured and weighed. Homogenisation and mixing of the recipe was carried out on a laboratory two-roll mill size $(180 \times 360 \mathrm{~mm})$ in accordance with ASTM-D3182. Roll speed ratio was at 1:1.25; while incorporation sequence and mixing time of additives were kept relatively uniform. A mill temperature of $65^{\circ} \mathrm{C}$ was maintained and sheeted composites were allowed for 24 hours maturation at $32^{\circ} \mathrm{C}$ before press curing. Press curing was in accordance to ASTMD1632-07. $150 \mathrm{Kg}$ pressure at a temperature of $150^{\circ} \mathrm{C}$ for an average period of 15 minutes as determined from ODR Model Rheometer was used for the composites curing process. Appropriate test samples were then prepared for evaluative examinations.

\subsection{Morphological Analysis}

Micro-structural analysis was performed using a Scanning Electron Microscopy (FEI Inspect 5-50 with XT Microscope data analysis software server). SEM magnification was at $1000 \mathrm{X}$ with a resolution of $80 \mu \mathrm{m}$. The sample surfaces were coated with a thin layer of gold using Bal-Tec SCD 005 Sputter Coater to provide electric conductivity. Secondary electron mode at a 10kv mapping acceleration voltage with full BSD was used. Particle properties were measured by volume and count using particle size analyser (Beckmann Coulter L5 200).

\subsection{Mechanical Analysis}

Test samples of the composites were subjected to various mechanical analyses in accordance with ASTM standard methods. Mechanical analyses evaluated were: Hardness (ASTM -D2240); Abrasion resistance (ASTM -D5963-04); Compressive strength (ASTM-D575-91); Tensile strength, Modulus, Elongation at break and Flexural analyses (ASTM -D3039/D). Three replicate specimens were used for each test and the data reported are the average of three tests. All test specimens were initially conditioned at $25^{0} \mathrm{C}$.

\subsection{Characterization}

\section{Results and Discussion}

The basic particle properties of the raw and carbonized coconut shell fibre at the various time of carbonization were examined. The results are presented in Table1. The results show that the $\mathrm{P}^{\mathrm{H}}$ increases from slightly acidic level to alkaline level as the carbonization period increased, because as the residual materials are being loss as a function of combustion time the metal content activity increases towards alkalinity[13, 5, 20]. There was a decrease of moisture content with the length of carbonization, thereby drastically eliminating bound moisture and a greater tendency of filler to adhere more to rubber matrix with the elimination of shrinkages. Ash content and loss on ignition increased with period of carbonization as the persistent temperature of $600^{\circ} \mathrm{C}$ burnsoff all residual materials into ash level and thereby leading to degradation in particles reinforcing properties [21, 
22]. The iodine adsorption number is a measure of the surface area of the filler; the higher the value, the finer the reactivity and reinforcement ability $[12,23]$. The bulk density decreases with the period of carbonization. The density is influenced by the particle size and structure of the fibre and the lower the particle size, the lower the density and therefore the better the filler-matrix interaction. But the more prolonged the carbonization period; the morphological three dimensional structures diminish thereby leading to reversion in reinforcement $[13,24]$. The oil absorption values indicate that the aggregate structure of the coconut shell fibre gets stronger with increase in carbonization period giving an indication of the filler to interact more with the rubber matrix [12]. Particle dimensions: length, width and diameter decrease as the carbonization is sustained .Smaller particles have the ability to wet rubber surface more and therefore more reinforcement. Particle conductivity also increases with sustained carbonization possibly because of more regularly arranged particles [25].

Table 1: Characterization of Raw and Carbonized Coconut Shell Fibre at $600^{\circ} \mathrm{C}$ at the Various Period of (1-5) Hours.

\begin{tabular}{|c|c|c|c|c|c|c|}
\hline Parameter & Raw & $1 \mathrm{Hr}$ & $2 \mathrm{Hrs}$ & 3Hrs & 4Hrs & $5 \mathrm{Hrs}$ \\
\hline $\mathrm{P}^{\mathrm{H}}$ of Slurry @ 32 $\mathrm{C}$ & 6.25 & 6.42 & 6.89 & 7.25 & 7.36 & 7.89 \\
\hline Moisture Content $(\%)$ & 11.00 & 7.56 & 5.80 & 3.50 & 2.10 & 1.02 \\
\hline Ash Content (\%) & 2.40 & 3.52 & 4.20 & 6.85 & 8.24 & 9.10 \\
\hline Loss on Ignition $\left(800^{\circ} \mathrm{C}\right)(\%)$ & 32.00 & 38.50 & 40.10 & 42.80 & 51.80 & 55.40 \\
\hline Iodine Adsorption Number (mg/g) & 0.07 & 0.12 & 0.141 & 2.90 & 4.60 & 6.15 \\
\hline Bulk Density (g/ml) & 0.98 & 0.90 & 0.86 & 0.80 & 0.42 & 0.15 \\
\hline Oil Absorption (kg) & 6.02 & 6.19 & 6.35 & 6.45 & 6.91 & 6.98 \\
\hline Conductivity $(\mu \mathrm{m})$ & 0.83 & 0.88 & 1.42 & 3.20 & 3.46 & 3.40 \\
\hline Length $(\mu \mathrm{m})$ & 0.38 & 0.30 & 0.26 & 0.15 & 0.12 & 0.09 \\
\hline Width $(\mu \mathrm{m})$ & 0.02 & 0.09 & 0.006 & 0.003 & 0.002 & 0.001 \\
\hline Diameter $(\mu \mathrm{m})$ & 0.05 & 0.02 & 0.09 & 0.006 & 0.005 & 0.002 \\
\hline Lumen $(\mu \mathrm{m})$ & 0.01 & $=$ & - & - & - & - \\
\hline
\end{tabular}

\subsection{Morphological Results}

It is clear from the micro-structural examination shown in Fig. 1, that particle agglomeration becomes finer and smaller in patches as the carbonization period is sustained. Beyond 4 hours period the particles become too powdery and tend to become ashes. At this higher period of carbonization the micro molecular structures and networks are damaged and therefore loss of bond strength became more pronounced as depicted in Fig. 1 .

Carbonization at $600^{\circ} \mathrm{C}$ for $1 \mathrm{hr}-3 \mathrm{hrs}$ shows the homogenous surface of the coconut shell fibre with less or no agglomeration. Agglomerations became significant at $3 \mathrm{hrs}$ of carbonization up to 4 hrs; after which the reinforcing agglomerates degenerate to ashes with less reinforcement as filler-matrix interaction drastically decline [11]. Coconut shell fibre is a lignocellulosic material where Polar hydroxyl groups on its surface may have the tendency to agglomerate through the formation of the hydrogen bonding. The agglomeration may then produce discontinuity in the matrix, which subsequently creates stress concentration point in the composites samples. But the sustained longer periods beyond $4 \mathrm{hrs}$ of carbonization at $600^{\circ} \mathrm{C}$ will completely disintegrate the stability of the hydrogen bonding and therefore leading to a weak polar interface between the filler and the rubber matrix. This suggests the weak mechanical properties at carbonization beyond $3 \mathrm{hrs}$ at $600^{\circ} \mathrm{C}[11,26]$. The tendency of filler-matrix interaction improved much more at $3 \mathrm{hrs}$ of sustained carbonization at $600^{\circ} \mathrm{C}$ and levels up near 4 hours of carbonization. Beyond $4 \mathrm{hrs}$, the filler-matrix interaction strongly decrease as the micro-structural pattern forms less agglomeration and existing hydrogen bonding disintegrate. Monographs image of the carbonized filler samples at $600^{\circ} \mathrm{C}$ for (1-5) hrs at full BSD showed that particle properties weighted by volume and by count decrease with increase time of carbonization and eventually become powdery with less fibre strength beyond 3 hours of carbonization. See Tables (2) and (3). 

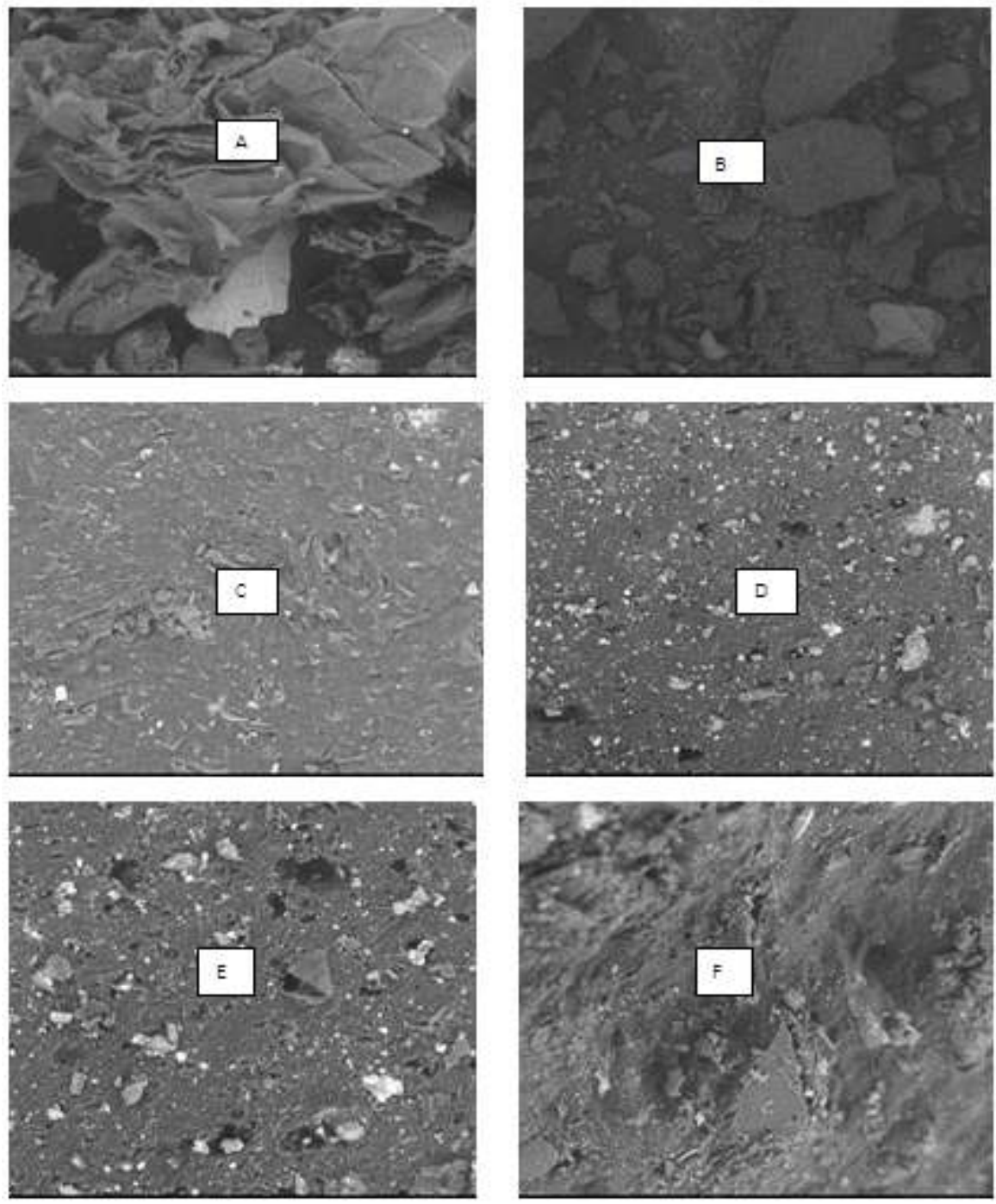

Figure 1: Micro-Structural Examination Of Filler-Matrix Interaction As A Function Of Carbonization Time: (A) Raw Coconut Shell Fibre, (B) After $1 \mathrm{Hr}$ Of Carbonization, (C) After 2 Hrs Of Carbonization, (D) After 3 Hrs Of Carbonization, (E) After 4 Hrs Of Carbonization And (F) After 4 Hrs Of Carbonization.

Table 2: Properties Weighted by Volume at Varying Carbonization Period of (1-5) Hours at $600^{\circ} \mathrm{C}$.

\begin{tabular}{|lcccccc|}
\hline Property $($ Average $)$ & CFP & 1Hr & 2Hrs & 3Hrs & 4Hrs & 5Hrs \\
\hline Circle equivalent diameter $(\mu \mathrm{m})$ & 40.3 & 39.1 & 31.8 & 28.2 & 25.6 & 16.4 \\
Major axis $(\mu \mathrm{m})$ & 53.1 & 50.2 & 46.5 & 31.3 & 29.1 & 19.8 \\
Minor axis $(\mu \mathrm{m})$ & 30.9 & 28.9 & 23.4 & 20.6 & 20.1 & 14.6 \\
Circumference $(\mu \mathrm{m})$ & 206 & 198 & 172 & 152 & 149 & 122 \\
Convex hull $(\mu \mathrm{m})$ & 161 & 153 & 145 & 120 & 118 & 98 \\
Circumscribed circle diameter $(\mu \mathrm{m})$ & 64.3 & 60.1 & 55.9 & 48.8 & 46.8 & 30.5 \\
Pixel count & 2567 & 2489 & 2410 & 2127 & 2115 & 1535 \\
Aspect ratio & 0.596 & 0.585 & 0.544 & 0.255 & 0.248 & 0.195 \\
Circularity & 0.45 & 0.41 & 0.36 & 0.24 & 0.20 & 0.09 \\
Convexity & 0.824 & 0.800 & 0.766 & 0.451 & 0.431 & 0.215 \\
Elongation & 0.404 & 0.385 & 0.381 & 0.312 & 0.310 & 0.142 \\
Grayscale & 90.7 & 90.1 & 50.8 & 34.9 & 34.1 & 10.8 \\
\end{tabular}


Table 3: Properties Weighted by Count at Varying Carbonization Period of (1-5) Hours at $600^{\circ} \mathrm{C}$.

$\begin{array}{llccccc}\text { Property }(\text { Average }) & \text { CFP } & \mathbf{1 H r} & \mathbf{2 H r s} & \mathbf{3 H r s} & \mathbf{4 H r} & \mathbf{5 H r s} \\ \text { Circle equivalent diameter }(\mu \mathrm{m}) & 30 & 26 & 22 & 16 & 14 & 09 \\ \text { Major axis }(\mu \mathrm{m}) & 40 & 35 & 29 & 20 & 18 & 12 \\ \text { Minor axis }(\mu \mathrm{m}) & 23 & 20 & 18 & 14 & 15 & 10 \\ \text { Circumference }(\mu \mathrm{m}) & 137 & 130 & 120 & 95 & 90 & 74 \\ \text { Convex hull }(\mu \mathrm{m}) & 117 & 111 & 100 & 75 & 71 & 54 \\ \text { Circumscribed circle diameter }(\mu \mathrm{m}) & 47.2 & 40.1 & 37.8 & 28.5 & 27.2 & 19.9 \\ \text { Area }\left(\mu \mathrm{m}^{2}\right) & 767 & 685 & 514 & 295 & 265 & 189 \\ \text { Pixel count } & 1370 & 1296 & 1149 & 1058 & 1040 & 954 \\ \text { Aspect ratio } & 0.592 & 0.548 & 0.452 & 0.210 & 0.198 & 0.110 \\ \text { Circularity } & 0.519 & 0.511 & 0.489 & 0.294 & 0.281 & 0.112 \\ \text { Convexity } & 0.877 & 0.866 & 0.715 & 0.350 & 0.312 & 0.152 \\ \text { Elongation } & 0.408 & 0.394 & 0.365 & 0.218 & 0.210 & 0.142 \\ \text { Grayscale } & 91.7 & 85.9 & 69.5 & 48.8 & 43.9 & 28.5\end{array}$

The particle characteristics reduce averagely with the particle size. As the period of carbonization at $600^{\circ} \mathrm{C}$ is sustained, all descriptive particle characteristics decrease as shown in Tables (2) and (3). The smaller the particle size the more they are properly packed and loaded into the rubber matrix thereby initiating more composite properties reinforcement .But this seemly good trend got to its optimum as observed in the mechanical analysis at 3 hours of carbonization and starts levelling off towards 4 hours and subsequently diminishes beyond 4 hours of sustained carbonization at $600^{\circ} \mathrm{C}$. The possible reason was that as the particles properties tend towards finer and a more powdery nature at beyond 4 hours carbonization; strength of fibrous aspect reduces, excessive filler melting of the rubber matrix become more pronounced and the matrix could not retain extra finer particles in its pores; leading ultimately to poor network linkages and densities between ash borne fillers and rubber matrix. Also, the sustained time of carbonization leads to break down in the achieved carbon content into more of ash with weaker bond strength [27, 14, 28, 11, and 5]. Carbonization leads to increase in volume by area thereby contributing to interfacial bonding strength in the carbonized filler than for raw filler. This good result became optimum at 3 hours of carbonization and levelled up. Beyond 4 hours, the interfacial bonding strength in the carbonized filler decrease [29, 5].

\subsection{Mechanical Properties}

Mechanical properties of the coconut shell fibre composites depends on several factors such as the stress-strain behaviours of fibre and matrix phases, the phase volume fractions, the fibre concentration, the distribution and orientation of the fibre relative to one another [10]. Table 4 and Figs. 2 (a), (b) and (c), show the mechanical properties and graphical trends of the properties with varying time at a carbonization temperature of $600^{\circ} \mathrm{C}$.

Table 4: Mechanical Properties of Composites at Carbonization Temperature of $600^{\circ} \mathrm{C}$ from (1-5) Hours.

$\begin{array}{lllllll}\text { Properties } & \text { CFP } & \mathbf{1 H r} & \mathbf{2 H r s} & \mathbf{3 H r s} & \mathbf{4 H r s} & \mathbf{5 H r s} \\ \text { Hardness (Shore A) } & 64 & 68 & 75 & 80 & 78 & 60 \\ \text { Abrasion Resistance } & 24.40 & 25.32 & 29.95 & 36.55 & 35.40 & 18.45 \\ \text { Compressive Set (\%) } & 26.92 & 24.65 & 21.96 & 19.46 & 21.50 & 29.46 \\ \text { Tensile Strength (Mpa) } & 5.96 & 7.25 & 7.97 & 8.65 & 8.60 & 5.84 \\ \text { EAB (\%) } & 520.50 & 515.80 & 498.20 & 455.70 & 458.20 & 500.5 \\ \text { Modulus (\%) } & 2.85 & 3.20 & 3.84 & 4.25 & 4.22 & 2.60 \\ \text { Flexural Strength (Mpa) } & 1.99 & 1.65 & 1.42 & 1.38 & 1.36 & 1.25\end{array}$




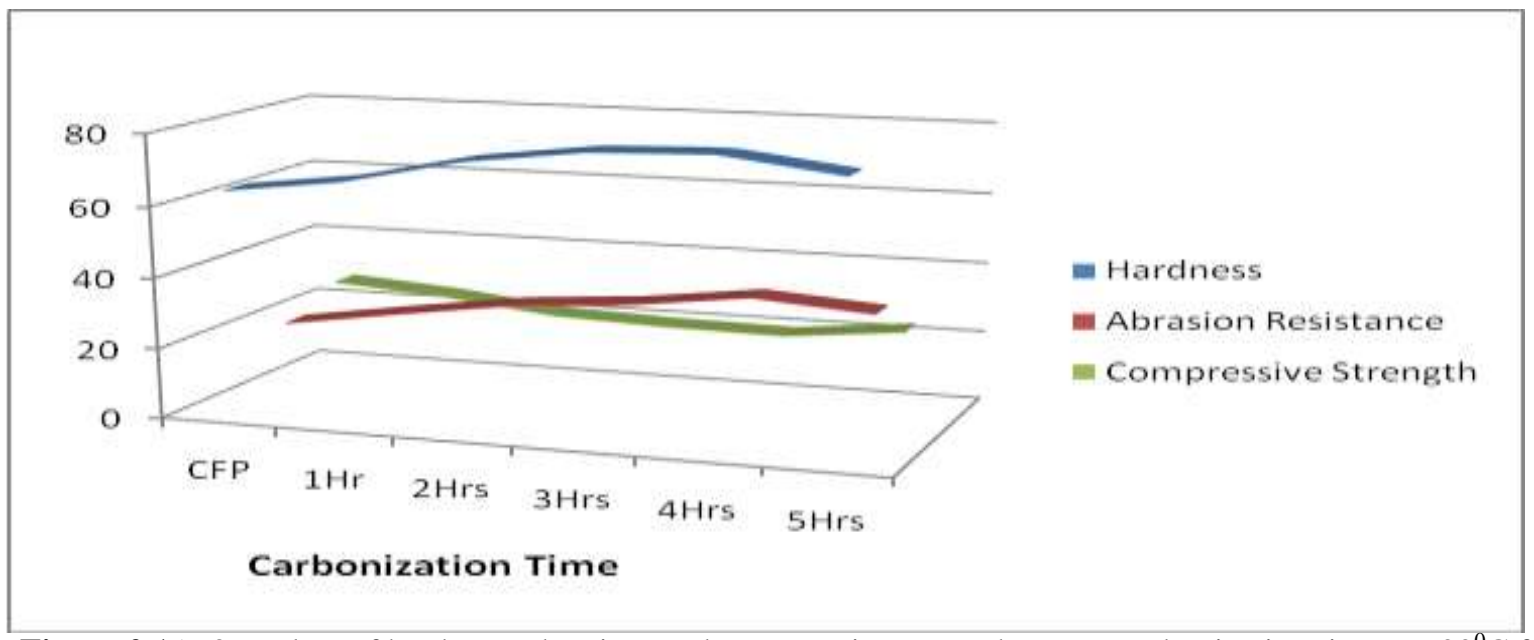

Figure 2 (a): 3-D plots of hardness, abrasion, and compressive strength versus carbonization time at $600^{\circ} \mathrm{C}$ for

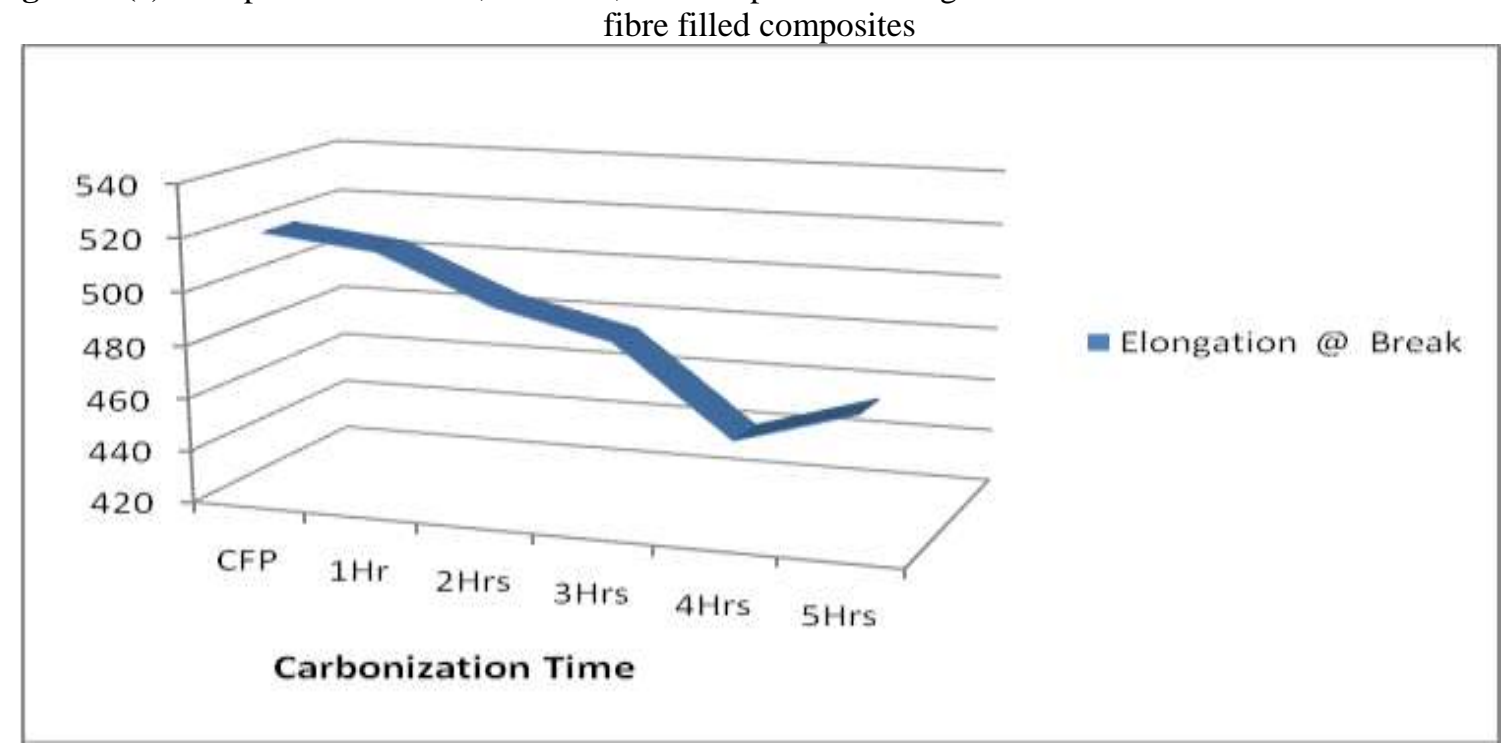

Figure 2 (b): 3-D plot of elongation @ break versus carbonization time at $600^{\circ} \mathrm{C}$ for fibre filled composites

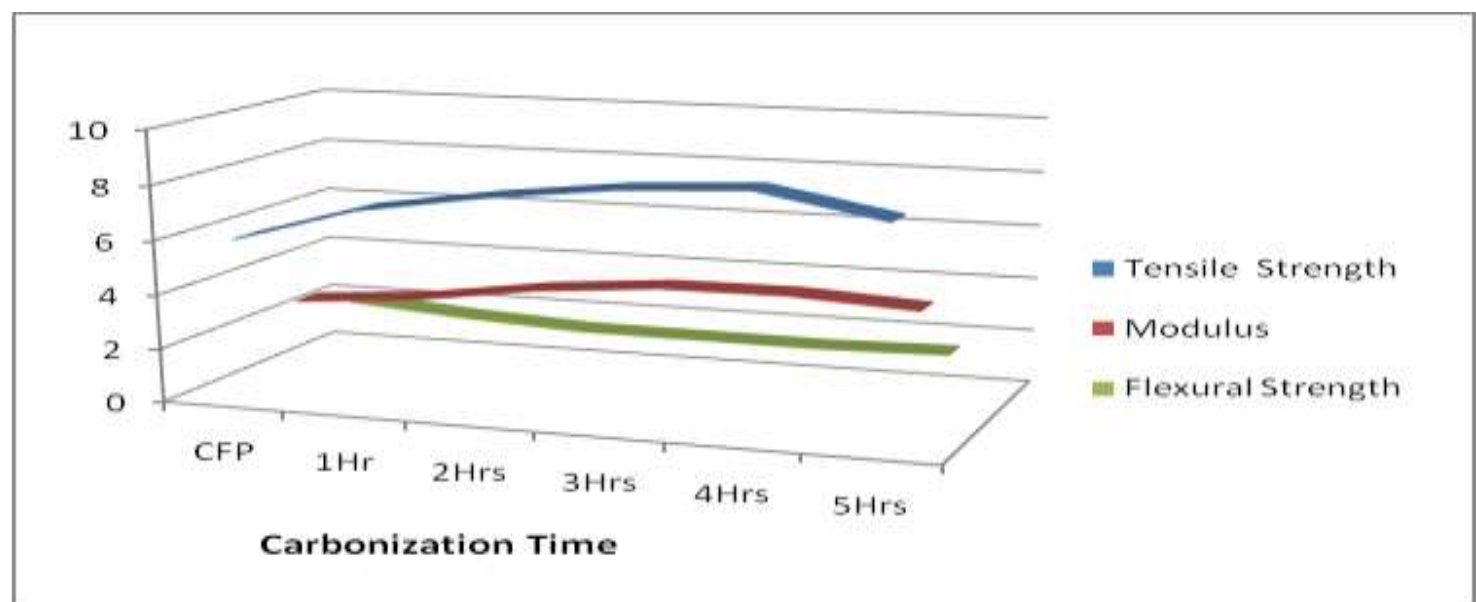

Figure 2 (c): 3-D plots of tensile strength, modulus and flexural strength versus carbonization time at $600^{\circ} \mathrm{C}$ for fibre filled composites

The shore "A" hardness of the composites increases with period of carbonization at $600^{\circ} \mathrm{C}$, gets to its optimum of $80 \mathrm{~A}$ at 3 hours of carbonization. This observed trend in hardness was influenced greatly by decrease in particle sizes. But beyond 3 hours of carbonization, the particle sizes have become too minute for a sustainable formation of network structure. Bond structure became weak and therefore less reinforcing [24, 4]. 
Abrasion resistance was remarkably influenced. At the carbonization temperature of $600^{\circ} \mathrm{C}$, resistance to composites wear increase with period of carbonization up to 3 hours and falls in value beyond 3 hours of carbonization. The bonding between filler particles and the rubber matrix was strong before and at 3 hours of carbonization, hence creating a high resistance to wear at beyond 3 hours of carbonization; even though particle sizes decrease. The decrease of particle sizes has become too powdery and finer that the network between filler and matrix had become weaker and particles could wear-off readily from composites surface and therefore dropping the resistance of subsequent composites $[13,5]$.

The compressive strength of composites decreases from raw state of fibre to 3 hours of fibre carbonization at $600^{\circ} \mathrm{C}$, possibly because the surface energy of the finer filler aggregate create a strong affinity between the filler and the rubber matrix thereby resulting in corresponding decrease in the compressive strength properties [9, 21]. Beyond 3 hours of carbonization, the filler aggregate become powdery and loose and consequently creates a weak affinity between the filler and the rubber matrix; thereby leading to increase in the compressive strength at $600^{\circ} \mathrm{C}$. The tensile strength, modulus and flexural properties increase with carbonization time to an optimum of 3 hours at sustained temperature of $600^{\circ} \mathrm{C}$. The observation was a direct response to decrease in particle sizes and filler aggregation. Smaller particle sizes will encourage reinforcement as strength of network will be regular and strong. But beyond 3 hours of carbonization, the particle sizes further decreases to minute and powdery forms thereby loosing the inherent strength and leading to the formation of weak network and consequently drops in previously achieved reinforcement.

The Elongation properties decrease as the carbonization period at $600^{\circ} \mathrm{c}$ increases to an optimum of 3hours of carbonization. The stiffness of the chain accounts for lower elongation at break with increase in carbonization period. Beyond 3 hours of carbonization the strength of the chain become weaker as a result of the powdery nature of the particles and consequently there was a gradual increase in elongation at break. The closer adherence of the particles become loose and filler-polymer interaction diminish.

Conclusions can be drawn as follows:

\section{Conclusion}

1. Carbonization of coconut fibre at $600^{\circ} \mathrm{C}$ gave optimum modification at 3 hours of carbonization.

2. Increase in carbonization time up to 3 hours create a finer morphological aggregate and hence improvement in the reinforcing ability of coconut fibre. Carbonization beyond 3 hours at $600^{\circ} \mathrm{C}$ will disperse the properly arranged finer aggregate and weaken interpenetrating network structure with direct consequence on lowering reinforcing properties.

3. Bond strength between fibre and rubber matrix gets stronger as carbonization time at $600^{\circ} \mathrm{C}$ increase up to an optimum of 3 hours. Beyond 3 hours of carbonization, particles become too powdery and scattered with clearly observed decrease in bond strength. Weaker bond strength will result in weak inter-phase reinforcement between filler and matrix.

4. Carbonization at $600^{\circ} \mathrm{C}$ for 3 hours gave optimum mechanical properties of hardness, abrasion resistance, compressive strength, tensile strength, modulus, elongation at break and flexural strength. Observed quality decrease beyond 3 hours of carbonization at $600^{\circ} \mathrm{C}$.

5. The use of modified coconut fibres in polymer matrix composites would convert waste to wealth, save the environment and expand possible areas of application of coconut fibre in engineering designs such as shock bearings, industrial fluid hoses, ship liners, constructional works and a vast coverage area in automobiles.

\section{References}

[1] G. A. Zickler, W. Wagermaier, S. S. Funari, M. Burghammer, O. Paris. In Situ X-ray Diffraction Investigation of Thermal Decomposition of Wood Cellulose. J. Anal. Appl. Pyrolysis 80, 2007, 134-140.

[2] N. Shebani, A. J. Van Reenen, M. Meincken, the Effect of Wood Extraction on the Thermal Stability of Different Wood-LLDPE Composites. Thermochim. Acta 481, 2009, 52-56.

[3] M. Poletto, J. Dettenborn, V. Pistor, M. Zeni, A. J. Zattera, Materials Produced from Plant Biomass, Part 1: Evaluation of Thermal Stability and Pyrolysis of Wood. Mat. Res. 13, 2010, 375-379.

[4] L. Howell, Understanding Wood Biodegradation through the Characterization of Crystalline Cellulose Nanostructures. Doctoral Thesis University of Maine, 2008

[5] F. P. Momoh, P. A. P. Mamza, C. E. Gimba, P. Nkeonye, Morphological Trends of Modified Coconut Fibre in Natural Rubber Reinforcement. Journal of Emerging Trends in Engineering and Applied Sciences, 7(4), 2016, 167-172.

[6] J. R. Araùjo, W. R. Waldman, M. A. De Paoli, Thermal Properties of High Density Polyethylene Composite with Natural Fibre: Coupling Agent Effect. Polym. Degrad.Stab.93, 2008, 1770-1775.

[7] J. G. Gwon, S. Y. Lee, S. J. Chun, Geum, G. H. Doh, J. H. Kim, Effects of Chemical Treatments of Hybrid Fillers on the Physical and Thermal Properties of Wood Plastic Composites. Elsevier Ltd, Composites: Part A41, 2010, 1491-1497.

[8] J. Móczó, B. Pukónszky, Polymer Micro and Nanocomposites: Structure, Interactions, Properties. J. Ind Eng Chem., 14, 2008, 53563.

[9] J. O. Akindapo, A. Harrison, O. M. Sanusi, Evaluation of Mechanical Properties of Coconut Shell Fibre as Reinforcement Material in Epoxy Matrix. IJERT, Vol. 3 Issue 2, 2014, 2337-3348.

[10] M. Sapuan, and M. Harimi, Mechanical Properties of Epoxy Coconut Shell Filler Particles Composite. The Arabian Journal for Science and Engineering, vol. 28, No. 2B, 2003, 171-181. 
[11] S. Husseinsyah, and M. Mostapha, the Effect of Filler Content on Properties of Coconut Shell Filler Polyester Composites, Malaysian Polymer Journal, Vol. 6 Vol 6, No 1, 2011, 87-97.

[12] G. N. Onyeagoro, Cure Characteristics and Physico-mechanical Properties of Carbonized Bamboo Fibre Filled Natural Rubber Vulcanisates. International Journal of Modern Engineering Research, vol. 2 issue 6, 2012, 4683-4690.

[13] M. D. Ayo, I. C. Madufor, L. O. Ekebafe, M. N. Chukwu, Effect of Filler Carbonizing Temperature on Mechanical Properties of Natural Rubber Composites, Researcher 3 (11), 2011, 7-10

[14] M. Ahmedna, M. Johnson, S .J.Clarke, W. E. Marshal, and R. M. Rao, Potential of Agricultural by Product Base Activated Carbon for Use in Raw Sugar Decolonization. J.Sci. Food. Agric., 75, 1997, 117-124.

[15] 15. H. Ismail, H. D. Rozman, R. M. affri, and Z. A. Ishak, Oil Palm Wood Flour Reinforced Epoxidized Natural Rubber Composites: Effects of Filler Content and size. European Polymer Journal, 33(10-11), 1997, 1627-1632.

[16] P. Suwatthana, and P. Cattaleeya, Compatibility Improvement of Rice Husk and Bagasse Ashes with Natural Rubber by Molten State Maleation. European Journal of Scientific Research, 43(3), 2010, 411-416.

[17] H. Osman, H. Ismail, and M. Mostapha, Effect of Maleic Anhydride Polypropelyne on Tensile, Water Absorption and Morphological Properties of Recycled Newspaper Filled Polypropylene/Natural Rubber Composites. Journal of Composites Materials, 44(12), 2010, 1477-1491.

[18] H. Zhang, Y. Wang, L. Zhang, and J. Yang, Preparation and Processing of Novel Polymer Materials. Journal of Applied Polymer Science, 97(3), 2004, 844-849.

[19] 19. A. Ansarifar, S. F. Shiah, and M. Bennett, Optimizing the Chemical Bonding between Silanized Silica Nanofiller and Natural Rubber and Assessing its Effect on the Properties of the Rubber. International Journal of Adhesion and Adhesives, 26(66), 2005, 454-463.

[20] 20. O.O. John,and I. A. Samuel, Potential of Carbonized Bagasse Filler in Rubber Product. Journal of Emerging Trends in Engineering and Applied Science, 1(2), 2010, 157-160.

[21] 21. L. Zhang, Y. Wang, V. Way, Y. Sin, and D. Yu, Morphology and Mechanical Properties of Clay/Styrenebutadiene Rubber Nanocomposites. Journal of Applied Polymer Science, 78(11), 2000, 1873-1878.

[22] 22. B. T. Poh, H. Ismail, and K. S. Tan, Polymer Testing, 21, 2002, 801.

[23] 23. F. E. Okieimen, and J. E. Imanah, Characterization of Agricultural Waste Products as Fillers in Natural Rubber Formulation. Nig. J. Polym.Technol.3 (1), 2003, 201-207.

[24] 24. Z.A. Ishak, and A. A. Baker, Europe Polymer Journal .31(3), 1995, 259-269.

[25] 25. J. Rout, M. Mistra, S. S. Tripathy, S. K. Nayak, A. K. Mohanty, The Influence of Fibre on the Performance of Coir-Polyester Composites. Composites Science and Technology, 61, 2001, 1303-1310.

[26] 26. K. S. Pradhan, S. E. Dwarakadasa, J. P. Reucroft, Processing and Characterization of Coconut Shell Powder Filled UHMWPE. Materials Science and Engineering A Journal, 367 (1-2), 2004, 57-62.

[27] 27. C. M. Blow, and C. Hepburn, Rubber Technology and Manufacture. Butterworth and Company Ltd, $3^{\text {rd }}$ edition London, 1971

[28] 28. D. Daniel, I. Punyanich, N. T. Quang, G. Fredderic, and N. Charoen, Graft Copolymers of Natural Rubber and Poly (dimethyl (acryloyloxymethyl) Phosphate) (NR-g-PDMAMP) or Poly (dimethyl (Methacryloyloxyethyl) Phosphate) (NR-g-PDMMED) from Photo-Polymerization in Latex Medium. European Polymer Journal, 45, 2009, 820-836.

[29] 29. G. K. Latinwo, D. S. Aribike, A. A. Susu, S. A. Kareem, Effects of Different Filler Treatments on the Morphology and Mechanical Properties of Flexible Polyurethane Foam Composites. Nature and Science Journal, 8(6), 2010, 23-31. 